\title{
Bee pollination of the endangered orchid Calanthe discolor through a generalized food-deceptive system
}

\author{
$\operatorname{AUTHOR}(\mathrm{S})$ :
}

Suetsugu, Kenji; Fukushima, Shigeki

\section{CITATION:}

Suetsugu, Kenji ... [et al]. Bee pollination of the endangered orchid Calanthe discolor through a generalized food-deceptive system. Plant Systematics and Evolution 2013, 300(3): 453-459

ISSUE DATE:

2013-08-23

URL:

http://hdl.handle.net/2433/196864

\section{RIGHT:}

The final publication is available at Springer via http://dx.doi.org/10.1007/s00606-0130894-7; この論文は出版社版でありません。引用の際には出版社版をご確認ご利用くだ さい。; This is not the published version. Please cite only the published version. 
1 Bee Pollination of the Endangered Orchid Calanthe discolor through a Generalized

2 Food-Deceptive System

3

4 Kenji Suetsugu • Shigeki Fukushima

5

6 Corresponding author:

$7 \quad$ Kenji Suetsugu

8 Mailing address: Graduate School of Human and Environmental Studies, Kyoto

9 University, Yoshida Nihonmatsu-cho, Sakyo, Kyoto, Japan, 606-8501

10 Phone number: +81-75-753-6853

11 Fax number: +81-75-753-6722

12 Email: kenji.suetsugu@gmail.com

14 K. Suetsugu

15 Graduate School of Human and Environmental Studies, Kyoto University,

16 Yoshida-Nihonmatsu-cho, Sakyo, Kyoto 606-8501, Japan

17 email: kenji.suetsugu@gmail.com

S. Fukushima

Chiba Prefectural Agriculture and Forestry Research Center, 1887-1, Haniya, Sanbu, Chiba 289-1223, Japan email: s.hkshm2@pref.chiba.lg.jp

24 Running title: Generalized Food Deception in Calanthe discolor 


\section{Abstract}

2

3 Calanthe discolor is a Japanese terrestrial orchid that is cultivated for its beautiful

4 flowers arranged in racemose inflorescences. Although, its propagation for horticultural

5 purposes has been studied extensively, resulting in the successful production of

6 seedlings little is known about the pollinators and breeding system of $C$. discolor in its

7 natural habitat. The current study, which combined field observations and pollination

8 experiments, was conducted to gain further insight into the reproduction of this

9 important orchid species. Three bee species: Eucera nipponensis, Osmia cornifrons and Apis cerana japonica, were found to be effective pollinators, transferring the pollinaria on their heads. However, pollination experiments also revealed that this species was self-compatible, although it was neither autogamous nor apogamous. The fruit set for the open-pollinated flowers was less than 10\%, suggesting a high degree of pollinator limitation, possibly as a result of the deceptive nature of this species. These results provide evidence that pollinator specificity is the primary mechanism of reproductive isolation between $C$. discolor and its close relative $C$. striata, because the latter species

17 is known to be exclusively pollinated by carpenter bee.

Keywords: Apis, Calanthe, Eucera, Osmia, orchid, pollination biology, pollinator limitation 
2

5

6

7

\section{Introduction}

The Orchidaceae is the largest family in the plant kingdom, comprising approximately 25000 species (Nillson 1992). The tremendous floral diversity and evolutionary radiation of orchid species is often linked to their intimate pollinator relationships (Johnson and Steiner 2000; Tremblay 1992; Cozzolino and Widmer 2005) with 60-70\% of orchid species being dependent on discrete pollinator lineages or even single species (Cozzolino and Widmer 2005).

The genus Calanthe comprises approximately 200 species of primarily terrestrial or lithophilic orchids distributed throughout Africa, Madagascar, China, Japan, tropical Asia, and Australia. While the pollination biology of Calanthe species remains largely unknown, seven species have been reported to be autogamous (Catling 1990). Meanwhile, it has also been suggested (Dressler 1993) that the analogous floral features shared with Epidendrum sp indicate a role for lepidopteran pollination system. Indeed, one report from the Ryukyu Islands (Japan) has shown that a nymphalid butterfly, Ideopsis similis similis, is able to transfer pollinia between flowers of Calanthe triplicata on its proboscis (Sugiura and Miyanaga 1996). Similarly, the cabbage white butterfly, Pieris rapae, has been confirmed as the pollinator of transplanted $C$. argenteostriata in southeast China (Zhang et al. 2010). These findings indicate that some Calanthe species bearing long spurs can be pollinated by butterflies or moths. However, there is also evidence that other Calanthe species might be pollinated by bees. For example, there have been several reports from various locations in Japan that medium-to-large species of bees from the genera Eucera, Xylocopa and Apis can carry the pollinia of Calanthe spp. (Ishihara 1957; Ishikawa and Suzuki 1992; Karasawa and Ishida 1998). Indeed, intensive observation of Calanthe striata revealed that it was 
1 pollinated exclusively by the carpenter bee, Xylocopa appendiculata circumvolans

2 (Sugiura 2013), In addition, interval photography showed that Calanthe reflexa was

3 pollinated by two bumblebee species: Bombus diversus diversus and B. hypocrita

$4 \quad$ (Sakata et al. 2013)

5

6 (Karasawa and Ishida 1998), although over-collection and habitat loss has placed almost

7 all of them in danger of extinction (Environment Agency of Japan 2000). The wide

There are currently twenty-six recorded taxa in the genus Calanthe in Japan variety of bright colours and pleasant fragrance of Calanthe species are highly prized in Japan, and Calanthe discolor with its racemose inflorescences is one of the most economically important of the Japanese ornamental orchids (Miyoshi and Mii 1988, 1995). However, in its native habitat $C$. discolor is categorized as an endangered species (Environment Agency of Japan 2000) and the probability of its extinction in Japan over the next 100 years is estimated to be almost 100\% (Environment Agency of Japan 2000). Despite its popularity, basic information regarding pollinators and other aspects of its reproduction system is lacking, with the exception of a few anecdotal studies suggesting pollination by medium-sized bees (Ishihara 1957; Ishikawa and Suzuki 1992; Karasawa and Ishida 1998).

C. striata is a closely related species that is often classified as an intraspecific variant of C. discolor (Iwatsuki 1995; Kim et al. 2008). The two species share the same morphological characteristics during vegetative growth but produce different flowers, those of $C$. striata being larger and emitting a stronger fragrance. The two species also differ in their coloration with the flowers of $C$. striata being uniformly yellow, whereas those of $C$. discolor are bicolored having brownish sepals and lateral petals with white lips. In addition, C. discolor is often cited as producing nectar (e.g. Kawarasawa 1998), while C. striata is known to be a food deceptive orchid (Sugiura 2013). Since 
1 pollinators often have a strong associative learning ability (Biernaskie et al. 2009),

2 food-deceptive species are usually expected to be strongly pollinator-limited, and

3 exhibit adaptive traits such as exaggerated floral signals (e.g. elongated spurs; Sletvold

4 and Ågren 2011) and optimized floral phenology (e.g. early flowering; Internicola and

$5 \quad$ Harder 2012) to promote pollinator attraction and pollination efficiency. Considering

6 that the diversity of floral characteristics can often be attributed to divergent selection

7 by pollinators, it is important to study whether the floral differences in C. discolor and

8 C. striata are a result of adoptions to different pollinators.

The current study was initiated to investigate four aspects of the reproductive biology of C. discolor: (1) to determine the potential for autonomous self-pollination (2) to confirm whether $C$. discolor produces nectar or is food deceptive (3) to identify candidate pollinators and ascertain any pollinator limitation (4) to determine whether $C$. discolor shares the same pollinator assemblage as its close relative C. striata.

\section{Materials and Methods}

Field observations and pollination experiments of Calanthe discolor were conducted in Sanbu City, Chiba Prefecture, from late April to early May of 2012 and 2013. The habitat was a coniferous plantation dominated by Cryptomeria japonica. The relative importance of daytime and nighttime visitors was evaluated by walking through the population and checking for the removal of pollinia in the mornings and evenings. This preliminary study revealed that pollinia were only removed during the day, and consequently the detailed observations of floral visitors were scheduled to coincide with the period of highest bee activity (0900 h-1800 h). The floral visitors were carefully observed to assess their pollination behavior, and some were captured for identification 
immediately after they had visited flowers.

The pollination experiments were conducted in early May 2012. Six flowering individuals were selected for the experiment each at the same phenological stage, just prior to anthesis, and bearing more than 15 flower buds. The number of flowers used for the experiment was limited to 15 from each plant, with the surplus flowers being removed before beginning the experiments. Each of the experimental flowers was in fine a mesh net early in the flowering season and assigned to one of three treatments: (1)

Pollinator-exclusion, to test for spontaneous self-pollination (6 shoots, 30 flowers), (2) Manual-autogamy to determine self-compatibility by placing pollinia onto the stigmas of the same flowers (6 shoots, 30 flowers), and (3) Manual-allogamy (6 shoots, 30 flowers). In addition to these treatments, 69 shoots were randomly tagged to assess the efficiency of pollination under unbagged conditions (69 shoots, 678 flowers in 2012; 124 shoots 1340 flowers in 2013). All the allogamous plants were spaced at least 5 meters from their nearest neighbor to avoid sampling within genetically identical plant. The experimental plants were intermittently monitored during the subsequent four weeks and scored for fruit set once the capsules had formed. The statistical differences between the pollinator-exclusion, manual-autogamy and manual-allogamy treatments were detected using Fisher's exact test with sequential Bonferroni correction.

All the mature indehiscent fruits from 6 experimental plants, as well as 20 fruits from 20 open-pollinated plants were collected in late September 2012, and silica dried for two weeks. Two from the manual-autogamy and one from the manual-allogamy treatments were excluded from the analysis as the mature fruits could not be detected in September. It is possibly that these fruits had aborted subsequent to the initial survey in late May. The dry seeds within each capsule were weighed to the nearest $0.1 \mathrm{mg}$ before 500 seeds were selected for dissection under a stereoscopic 
1 microscope to assess the ratio of seeds with an embryo compared to those without. The

2 effect of the pollination treatments on seed weight and the proportion of seeds having an

3 embryo were tested using the Student's $t$-test.

4

In addition, twenty flowers were selected at random from 5 individual $C$.

5 discolor plants in late April of 2012, and their spurs dissected under a stereoscopic

6 microscope to investigate whether the flowers produced nectar.

7

$8 \quad$ Results

9

The field observations revealed that the most abundant insect visitors were hymenopterans, with no adult lepidopteran visitors being observed. However, the larva of the lepidopteran Lemyra imparilis, known to be florivore of other orchids (e.g. Suetsugu 2013; Sugiura 2013), were detected. Members of the Diptera and Coleoptera were also observed visiting the flowers of $C$. discolor, although they did not exhibit typical pollinator behaviour, with most individuals merely alighting or resting on the flowers. However, food-seeking behavior was occasionally observed for the hoverfly Episyrphus balteatus and false blister beetle Oedemeronia lucidicollis, although they were unable to carry pollinia as a result of their small body size. The agromyzid fly, Japanagromyza tokunagai, known to infest various species of Japanese orchids (e.g. Suetsugu 2013; Sugiura 2013) was also observed visiting the flowers of C. discolor to lay its eggs in the young ovaries.

The most frequent visitors were bee species including Eucera nipponensis

23 (28\% of total floral visits), Osmia cornifrons (23\%) and Apis cerana japonica (10\%).

24 All three species exhibited nectar seeking and pollinating behaviour; shortly after alighting on the labellum, they held the labellum with their fore and middle legs and 
1 inserted their proboscises deeply into the spur (Fig. 2D). Whilst probing, their heads

2 were pushed against the tip of the column, thereby receiving pollinaria, or if already

3 laden transferring it to the stigmatic surface. The total time spent per flower was

4 typically less than 10 seconds, with the bees usually visiting one flower per

5 inflorescence before leaving. However, occasionally individuals of E. nipponensis and

6 O. cornifrons (two and three individuals, respectively) visited multiple flowers within

7 an inflorescence in succession.

The pollination experiments revealed that the three treatments:

9 pollinator-exclusion, manual autogamy and manual allogamy resulted in quite different levels of fruit set, with the proportion for each treatment being $0 \%, 86.7 \%$, and $93.3 \%$, respectively. In contrast, of the 678 and 1340 open-pollinated samples, only 44 and 16 bore fruit corresponding to a total fruit set of $6.5 \%$ and $1.2 \%$, respectively. The large discrepancy between the open-pollinated samples and the artificially fertilized flowers (both autogamous and allogamous) suggests that $C$. discolor experiences a high degree pollinator limitation in its native habitat. Although the manual autogamous treatment produced a lower fruit set than the allogamous treatment, this difference was not significant (Fisher's exact test, $P=0.85$ ), indicating that $C$. discolor is fully self-compatible. Furthermore, the seed mass and proportion of seeds with an embryo did not significantly differ between the two treatments (Student's $t$-test, $P=0.06, P=$ 0.42, respectively, Table. 2).

The results of the spur dissection experiment suggested that $C$. discolor does not produce nectar since no nectar secretions were detected in any of the 20 flowers examined.

Discussion 
1 A large discrepancy was observed between the fruit set of the open-pollinated subjects

2 (6.5\% in 2012 and 1.2\% in 2013) and the samples from both the manual autogamous

3 and allogamous pollination treatments (86.7\%, and 93.3\%, respectively). These results

4 suggest that the population investigated experiences a high degree of

5 pollinator-limitation, but is also consistent with the trend for relatively low fruit set

6 found in most orchid species (Neiland and Wilcock 1998; Tremblay et al. 2005).

Although C. discolor has previously been categorized as a nectariferous orchid, based on the presence of a flower spur (Karasawa and Ishida 1998), the dissection experiments produced no evidence of nectar secretion. The absence of floral rewards of any kind, combined with the nectar-seeking behaviour of the observed pollinators, as well as the absence of nectariferous flowers with a similar morphology and phenology to C. discolor, indicates that like other Calanthe species (Sakata et al. 2013; Sugiura 2013), C. discolor adopts a generalized strategy of food deception, whilst these results should not be considered conclusive as it possible that other populations do produce nectar, or that $C$. discolor is adapted to mimic a rewarding plant (or a set of plants) that did not occur in this particular location. Generalized food deceptive species often rely on pollination by naive insects and/or insects whose food resources have become depleted and thus early flowering is flavoured (Internicola et al. 2008, Internicola and Harder 2012). The flowering time of C. discolor (late April to early May) is early to middle stage of the main pollinator Eucera activity (April to June; Enju 2013). Thus, $C$. discolor ultilize not so much naive pollinator as pollinator whose food resources have become depleted. Because there are no sympatric co-blooming plants which share pollinators in our study site, the habitat separation from other nectariferous plants may be important for successful exploitation. 
Since pollinators often have a strong associative learning ability (Biernaskie et

2 al. 2009), it might be expected that generalized food-deceptive species would be

3 avoided (Li et al. 2011), with only a few non-rewarding flowers being visited before the

4 pollinators switch to alternative species (Dafni and Ivri 1981). This low pollinator

5 visitation, could in turn reduce the reproductive success of deceptive orchids (Neiland

6 and Wilcock 1998; Tremblay et al. 2005). The data from the current study provided

7 further support for this hypothesis with most pollinators only visiting one flower per

8 inflorescence resulting in a low fruit set (6.5\% in 2012 and 1.2\% in 2013). The value is

9 much lower than the average for both nectariferous and nectarless temperate orchids

$10 \quad(37.1 \% \pm 3.2 \%, n=84$ and $20.7 \% \pm 1.7 \%, n=130$, respectively; Tremblay et al. 2005), even considering the fact that annual fruiting success in orchids varies considerably (Curtis 1954; Sugiura et al. 2001; Sugiura et al. 2002; this study). Low pollination has also been linked to forest fragmentation (Tomimatsu and Ohara 2002; Huang et al. 2009). However, this seems unlikely since the study site was dominated by Cryptomeria, which has a dense canopy, and unmanaged Cryptomeria plantations are known to support very few understory plants (Ishii et al. 2008). Under such circumstance forest fragmentation might actually improve the richness and abundance of nectariferous plants, and indirectly favor insect visitation rates to orchids.

The data from the pollination experiments also confirmed that Calanthe discolor is self-compatible, as no significant differences in fruit set were detected between the manual-autogamy and manual-allogamy treatments. Many investigations of orchid breeding systems have demonstrated that self-pollination results in significantly lower rates of embryo formation relative to cross-pollination (e.g. Tremblay et al. 2005; Smithson 2006; Vale et al. 2011, 2013 but also see Gale 2007; Suetsugu and Fukushima 2013), even when there are no significant differences between the fruit set resulting 
1 from manual-autogamy and manual-allogamy treatments . This tendency appears to be

2 particularly evident in pollinator-dependent species, suggesting that inbreeding can

3 affect these species more than autogamous species (Tremblay et al. 2005). However,

4 there appeared to be no evidence of such inbreeding depression in the

5 pollinator-dependent $C$. discolor, with no significant difference being detected between

6 the proportion of seeds with a developed embryo from the manual-autogamy and

7 manual-allogamy treatments,. In addition, the seed mass and the proportion of seeds

8 with a developed embryo in unbagged plants were similar to those of manual-autogamy

9 and manual-allogamy treatments. Whilst it is possible that resource limitation negatively affected seed mass and the proportion of seeds with embryo, similar tendency on unbagged and controlled treatments suggested that pollinators would be as efficient as artificial pollination, in terms of quality of fruit.

The floral diversity of orchids has often been linked to the intimate and complicated interactions they have with their pollinators (Gill 1989). However, most estimates of a high incidence of single-pollinator species were based on observations of unique pollination systems, such as the sexually deceptive ones (Mant et al. 2002; Soliva and Widmer 2003). In contrast, subsequent studies have shown that generalized food deception orchids often attract a guild of locally available insect visitors (Cozzolino et al. 2004, 2005). The field observations in the current study supported this opinion, with at least three bee species (Eucera nipponensis, Osmia cornifrons and Apis cerana japonica), belonging to two different families, being observed pollinating the flowers of C. discolor.

No evidence was found to support the hypothesis of Dressler (1993) that

24 Calanthe species are likely to be pollinated by lepidopterans on the basis of their floral features being analogous to those of the lepidopteran-pollinated genus Epidendrum. 
1 Instead, the current study confirmed that $C$. discolor, similar to its close relative $C$.

2 striata (Sugiura 2013), successfully attracts bees for pollination, whilst this species has

3 relatively long spurs (ca. $7-10 \mathrm{~mm}$ ) and these is longer than the tongue lengths of the

4 pollinators (ca. 5-7 mm). Although a long spur is often thought to be associated with the

$5 \quad$ Lepidopteran pollination syndrome, rather than bee pollination (Dressler 1993), there is

6 growing evidence that the actual fauna pollinating a particular species is determined by

7 complex factors that include not only floral syndromes but also the local availability of

8 pollinators and historical adaptations to a habitat (Xie et al. 2013). Furthermore, it is

9 possible that the evolution of nectarless flowers may have released from selective constraint associated with mechanical fit of pollinator proboscis with access to nectar (Huang and Fenster 2007). Indeed, it has also been demonstrated that long spurs is favored by other bee-pollinating deceptive orchids (Sletvold and Ågren 2011). Further investigation is needed to reveal whether the phenotypic selection to longer spur exists in C. discolor.

Curiously, both $C$. discolor and C. striata have been considered conspecific by some authors (Kim et al. 2008), despite the differences in their flower size, coloration and fragrance (Park et al. 2010). The current study provides further evidence for reproductive isolation between these two species (i.e. difference of pollinator preference: C. discolor being pollinated by E. nipponensis, O. cornifrons and A. cerana japonica, while Calanthe striata seems to be pollinated exclusively by large carpenter bees; Sugiura 2013). Furthermore, C. discolor lacks the strong and/or very sweet scents which is associated with Xylocopa-pollinated orchids (e.g. Braga 1977; Díaz and Vale 2001; Sugiura 2013). Although it should be noted that differences of floral visitors can be partially explained by local availability of pollinators in our study and Sugiura's study site, the floral characteristics, such as perianth size and the height of the 
1 rostellum/stigma and fragrance are also likely to reflect adaptations to their own

2 pollinator assemblages. However, since $C$. discolor is known to hybridize with $C$.

3 striata in wild populations (Kim et al. 2008) further investigation is required to

4 ascertain whether these species share pollinator assemblages in sympatric populations.

5

6 Acknowledgements

7

8 We thank Makoto Kato and Yuta Nakase for identifying the bees and hoverflies. This

9 study was partly supported by the Japan Society for the Promotion of Science Research

10 Fellowships for Young Scientists Grant to KS.

\section{References}

14 Biernaskie JM, Walker SC, Gegear RJ (2009) Bumblebees learn to forage like bayesians. Am Nat 174:413-423

Braga PIS (1977). Aspectos biológicos das orchidaceae de uma campina na amazônia central. Acta Amazon 7:1-89

Catling PM (1990) Auto-pollination in the Orchidaceae. Orchid Biol Rev Perspect $5: 121-158$

Cozzolino S, Widmer A (2005) Orchid diversity: An evolutionary consequence of deception? Trends Ecol Evol 20:487-494

Cozzolino S, D'Emerico S, Widmer A (2004) Evidence for reproductive isolate selection in Mediterranean orchids: Karyotype differences compensate for the lack of

24 pollinator specificity. Proc R Soc B 271:S259-S262

Curtis JT (1954) Annual fluctuation in rate of flower production by native 
$1 \quad$ Cypripediums during two decades. Bull Torrey Bot Club 81:340-352

2 Dafni A, Ivri Y (1981) Floral mimicry between Orchis israelitica Baumann and Dafni

3 (Orchidaceae) and Bellevalia flexuosa Boiss. (Liliaceae). Oecologia 49:229-232

4 Díaz I, Vale A (2001). Actividad polinizadora y aspectos conductuales de la abeja

$5 \quad$ xylocopa cubaecola lucas (hymenoptera: Apoidea) en condiciones naturales.

$6 \quad$ Fitosanidad 5:25-30

7 Dressler RL (1993) Phylogeny and Classification of the Orchid Family. Dioscorides $8 \quad$ Press, Portland Oregon.

9 Enju (2013) Japanese insects Bun-ichi Sogo Shuppan, Japan Tokyo.

Environment Agency of Japan (2000) Threatened wildlife of Japan, Red Data Book. (Vascular plants). Japan Wildlife Research Center, Tokyo.

Gale S (2007) Autogamous seed set in a critically endangered orchid in Japan: pollination studies for the conservation of Nervilia nipponica. Plant Syst Evol 268:59-73

Gill DE (1989) Fruiting failure, pollination inefficiency, and speciation in orchids. In Otte D and Endler JA (eds) Speciation and its consequences. Sinauer Associates Inc, Sunderland, pp. 458-481

Huang BQ, Sun YN, Yu XH, Luo YB, Hutchings MJ, Tang SY (2009) Impact of proximity to a pathway on orchid pollination success in Huanglong National Park, South-West China. Biol Conserv 142:701-708

Huang SQ, Fenster CB (2007). Absence of long-proboscid pollinators for long-corolla-tubed himalayan Pedicularis species: Implications for the evolution of corolla length. Int J Plant Sci 168:325-331

Internicola AI, Harder LD (2012). Bumble-bee learning selects for both early and long flowering in food-deceptive plants. Proc R Soc B 279:1538-1543 
1 Ishihara T (1957) On honeybee's 'tiara'. Shin-Kontyu 10:14-15

2 Ishikawa R, Suzuki K (1992) Tetralonia nipponensis. Insectarium 29

3 Ishii HT, Maleque MA, Taniguchi S (2008). Line thinning promotes stand growth and

4 understory diversity in japanese cedar (cryptomeria japonica D. don) plantations. J

$5 \quad$ Forest Res 13:73-78

6 Johnson SD, Steiner KE (2000) Generalization versus specialization in plant pollination

$7 \quad$ systems. Trends Ecol Evol 15:140-143

8 Karasawa K, Ishida G (1998) Calanthe. Yasaka-Shobo Inc, Tokyo.

9 Kim KS, Kim JS, Park JH (2008) Aseptic germination of F1 hybrid seed by

10 inter-species pollination of Calanthe discolor Lindl. and C. discolor for C. sieboldii

11 (Decne.) Ohwi. Kor J Plant Res 21:341-345

Li P, Zheng GL, Dafni A, Luo YB (2010) Reproductive biology of an alpine orchid Phaius delavayi. Plant Syst Evol 286:167-173

Li P, Huang BQ, Pemberton RW, Luo YB, Cheng J (2011) Floral display influences male and female reproductive success of the deceptive orchid Phaius delavayi. Plant Syst Evol 296:21-27

Mant JG, Schiestl FP, Peakall R, Weston PH (2002) A phylogenetic study of pollinator conservatism among sexually deceptive orchids. Evolution 56:888-898

Miyoshi K, Mii M (1995) Enhancement of seed germination and protocorm formation in Calanthe discolor (Orchidaceae) by $\mathrm{NaOCl}$ and polyphenol absorbent treatments. Plant Tissue Culture Lett 12:267-272

Miyoshi K, Mii M (1988) Ultrasonic treatment for enhancing seed germination of terrestrial orchid, Calanthe discolor, in asymbiotic culture. Sci Hortic 35:127-130

Neiland MRM, Wilcock CC (1998) Fruit set, nectar reward, and rarity in the Orchidaceae. Am J Bot 85:1657-1671 
1 Park JM, Whang SS, So S, Lim PO, Lee H, Koo JC (2010) Identification of

2 differentially expressed genes in flower buds of Calanthe discolor and C. sieboldii. J

$3 \quad$ Plant Biol 53:24-31

4 Sakata Y, Sakaguchi S, Yamasaki M (2013) Does community-level floral abundance

5 affect the pollination success of a rewardless orchid, Calanthe reflexa Maxim.? Plant

$6 \quad$ Spec Biol doi: 10.1111/1442-1984.12004

$7 \quad$ Smithson A (2006) Pollinator limitation and inbreeding depression in orchid species

$8 \quad$ with and without nectar rewards. New Phytol 169:419-430

9 Soliva M, Widmer A (2003) Gene flow across species boundaries in sympatric, sexually deceptive Ophrys (Orchidaceae) species. Evolution 57:2252-2261

Sletvold N, Ågren J (2011) Nonadditive effects of floral display and spur length on reproductive success in a deceptive orchid. Ecology 92:2167-2174

Suetsugu K, Fukushima S (2013) Pollination biology of the endangered orchid Cypripedium japonicum in a fragmented forest of Japan. Plant Spec Biol doi: $10.1111 / 1442-1984.12016$

Suetsugu K (2013) Autogamous fruit set in a mycoheterotrophic orchid Cyrtosia septentrionalis. Plant Syst Evol 299: 481-486

Sugiura N (2013) Specialized pollination by carpenter bees in Calanthe striata (Orchidaceae), with a review of carpenter bee pollination in orchids. Bot J Linn Soc 171:730-743

Sugiura N, Miyanaga R (1996) A male Radena similes similes (Lepidoptera: Danaidea) with a pollinarium of Calanthe triplicata (Orchidaceae). Chukogu Konchu 10

Sugiura N, Goubara M, Kitamura K, Inoue K (2002) Bumblebee pollination of Cypripedium macranthos var. rebunense (Orchidaceae); a possible case of floral mimicry of Pedicularis schistostegia (Orobanchaceae). Plant Syst Evol 235:189-195 
1 Sugiura N, Fujie T, Inoue K, Kitamura K (2001) Flowering phenology, pollination, and

2 fruit set of Cypripedium macranthos var. rebunense, a threatened lady's slipper

$3 \quad$ (Orchidaceae). J Plant Res 114:171-178

4 Tomimatsu H, Ohara M (2002) Effects of forest fragmentation on seed production of the

$5 \quad$ understory herb Trillium camschatcense. Conserv Biol 16:1277-1285

6 Tremblay RL (1992) Trends in the pollination ecology of the Orchidaceae: evolution

$7 \quad$ and systematics. Can J Bot 70:642-650

8 Tremblay RL, Ackerman JD, Zimmerman JK, Calvo RN (2005) Variation in sexual

9 reproduction in orchids and its evolutionary consequences: A spasmodic journey to

10 diversification. Biol J Linn Soc 84:1-54

11 Vale Á, Rojas D, Álvarez JC, Navarro L (2011) Breeding system and factors limiting fruit production in the nectarless orchid Broughtonia lindenii. Plant Biol 13:51-61

Vale A, Rojas D, Álvarez JC, Navarro L (2013) Distribution, habitat disturbance and pollination of the endangered orchid Broughtonia cubensis (Epidendrae: Laeliinae). Bot J Linn Soc DOI: 10.1111/boj.12042

Xie PW, Luo Z, Zhang D (2013). Syrphid fly pollination of Guihaiothamnus acaulis (rubiaceae), a species with "butterfly" flowers. J Syst Evol 51:86-93

Zhang H, Li L, Liu Z, Luo Y (2010) The butterfly Pieris rapae resulting in the reproductive success of two transplanted orchids in a botanical garden. Biodivers Science 18:11-18 
1 Figure legends
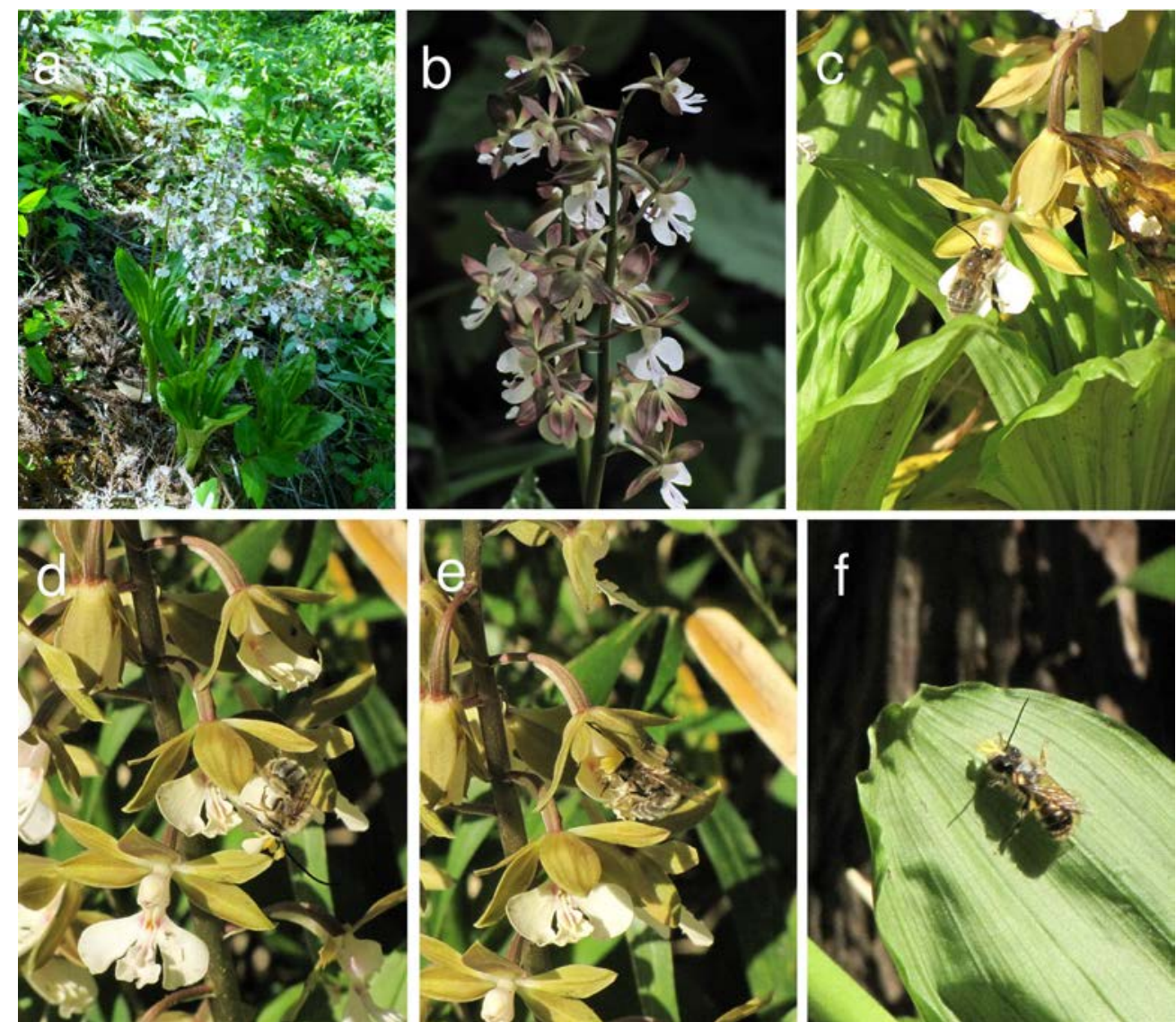

3 Figure 1. Flowers of Calanthe discolor and its visitors. (a) Flowering individuals, (b)

4 inflorescence, (c-e) Eucera nipponensis visiting a flower and carrying pollinaria on its

$5 \quad$ head, (f) Osmia cornifrons carrying pollinaria on its head.

6

7

8

9 
Table 1. The identity of insect taxa and total number of insect visitors

\begin{tabular}{rrrrr}
\hline Insect species & Insect order & No. of & Pollinia & Pollinia \\
& visitors & removal & deposition \\
\hline Eucera nipponensis & Hymenoptera & 11 & 8 & 3 \\
Osmia cornifrons & Hymenoptera & 9 & 5 & 2 \\
Apis cerana japonica & Hymenoptera & 4 & 2 & 0 \\
Episyrphus balteatus & Diptera & 5 & 0 & 0 \\
Eupeodes corollae & Diptera & 2 & 0 & 0 \\
Japanagromyza tokunagai & Diptera & 1 & 0 & 0 \\
Sphaerophoria sp. & Diptera & 1 & 0 & 0 \\
Oedemeronia lucidicollis & Coleoptera & 2 & 0 & 0 \\
Macrolagria rufobrunnea & Coleoptera & 2 & 0 & 0 \\
Lemyra imparilis (larva) & Lepidoptera & 3 & 0 & 0 \\
\hline
\end{tabular}

1

Table 2. The effect of pollination treatment on fruit set, seed mass and proportion of seeds with embryo.

\begin{tabular}{lrrrr}
\hline Treatment & Pollinator exclusion & Manual autogamy & Manual allogamy & Unbagged \\
\hline Fruit set & $0 / 30$ & $26 / 30$ & $28 / 30$ & $44 / 678$ \\
Seed mass (mg) & - & $20.8 \pm 6.2$ & $23.6 \pm 6.5$ & $29.1 \pm 6.9$ \\
Seed with embryo (\%) & - & $86.9 \pm 9.5$ & $87.5 \pm 7.8$ & $87.9 \pm 7.5$ \\
\hline
\end{tabular}

$\mathrm{N} / \mathrm{n}$, number of developed fruits/number of examined flowers; Seed mass and seeds with embryo are indicated mean \pm SD. 